\title{
IDENTIFIKASI HAZARD PADA PROSES PRODUKSI BILLET PADA AREA TUNGKU PELEBURAN DENGAN METODE HIRARC (STUDI KASUS: PT. XYZ)
}

\author{
Rani Aulia Imran \\ Jurusan Teknik Industri, Fakultas Teknik, Universitas Jenderal Soedirman \\ e-mail: rani.aulia.imran@unsoed.ac.id
}

\begin{abstract}
ABSTRAK
PT. XYZ merupakan salah satu perusahaan industri baja berskala besar di Indonesia. Perusahaan ini merupakan perusahaan yang sebagian besar proses produksinya menggunakan mesin dan peralatan serta area yang memiliki potensi bahaya yang tinggi apabila tidak dilakukan pengendalian. Tujuan dari penelitian ini adalah untuk mengetahui apa saja jenis potensi hazard, tingkat risiko dari hazard yang ditemukan serta upaya pengendaliannya dengan menggunakan metode HIRA, yang terdiri dari identifikasi bahaya, penlaian risiko, dan pengendalian risiko. Penelitian ini merupakan penelitian observasional. Data primer didapatkan melalui hasil observasi dan wawancara yang kemudian disajikan dalam bentuk tabel lalu dianalisis secara deskriptif. Hasil penelitian menunjukan bahwa pada proses produksi billet area peleburan terdapat 10 temuan hazard dengan 23 risiko kecelakaan dan penyakit akibat kerja dari 3 aktivitas pekerjaan. Berdasarkan hasil penilaian, dari 23 risiko pada proses produksi billet area peleburan terdapat 6 jenis risiko pada level low, 12 jenis risiko pada level medium, dan 5 jenis risiko pada level high. Adapun kegiatan yang telah dilakukan perusahaan untuk mengurangi risiko terjadinya hazard, namun ada beberapa upaya pengendalian yang masih belum dilakukan oleh perusahaan yaitu penggantian jenis tungku, penggunaan material handling pada beberapa kegiatan, mengisolasi ruangan sumber kebisingan, serta pendisiplinan dalam prosedur kerja dan penggunaan APD.
\end{abstract}

Kata kunci: Hazard, Pengendalian risiko, HIRA.

\begin{abstract}
PT. PSI is a large-scale steel industry company in Indonesia. This company is a company that most of the production process uses machinery and equipment as well as areas that have a high potential for danger if not controlled. The purpose of this study is to find out what types of potential hazards, the level of risk discovered and its efforts to control using the HIRA method, which consists of hazard identification, risk assessment, and risk control. This research is an observational study. Primary data obtained through observations and interviews are then presented in tabular form and analyzed descriptively. The results showed that in the smelting billet production process, there were 10 hazard findings with 23 occupational risks and occupational diseases from 3 work activities. Based on the results of the risk assessment, of the 23 risks in the smelting billet production process, there are 6 types of risk at low level, 12 types of risk at medium level, and 5 types of risk at high level. The activities undertaken by the company to reduce the risk of hazard occurrences, however, there are some control efforts that have not been carried out by the company, namely the replacement of the furnace type, the use of material handling in several activities, isolating the noise source room, and disciplining in work procedures and use of PPE.
\end{abstract}

Keywords: Hazard, Risk Control, HIRA.

\section{PENDAHULUAN}

Pelaksanaan keselamatan dan kesehatan kerja (K3) sampai saat ini masih memprihatinkan. Kecelakaan kerja sering terjadi baik di sektor pertanian, pertambangan dan energi, industri dan manufaktur, konstruksi, transportasi dan sektor lainnya. Menurut laporan ILO di seluruh dunia sedikitnya 2,2 juta orang meninggal akibat kejadian dan penyakit yang berkaitan dengan kerja. Keselamatan dan kesehatan kerja (K3) Indonesia menduduki urutan ke-5 (terburuk) dibandingkan Singapura, Malaysia, Thailand dan Filipina [1]. 


\section{Rani Aulia Imran}

Dalam beberapa tahun terakhir, angka kecelakaan kerja di Indonesia terus meningkat. Menurut data yang dilansir oleh BPJS Ketenagakerjaan, pada tahun 2017 angka kecelakaan kerja yang dilaporkan sebanyak 123.041 kasus, sementara tahun 2018 mencapai 173.105 kasus [2]. Maka dari itu perlu dilakukan pengendalian terhadap risiko risiko terjadinya kecelakaan untuk mengurangi angka kecelakaan kerja.

Pengendalian potensi penyakit akibat kerja atau pun akibat kecelakaan kerja dapat dilakukan dengan mengidentifikasi sumber bahaya dan faktor-faktor yang dapat menimbulkan suatu penyakit. Mengingat pentingnya kesehatan dan keselamatan tenaga kerja di Indonesia, pemerintah mengeluarkan peraturan, yaitu undang-undang nomor 1 tahun 1970 tentang keselamatan kerja yang menyebutkan bahwa setiap tenaga kerja berhak mendapatkan keselamatannya dalam melakukan pekerjaan untuk kesejahteraan hidup dan produktifitas nasional. Hal ini merupaka bentuk perhatian pemerintah untuk melindungi kesehatan dan keselamatan tenaga kerja. Namun selain pemerintah, program keselamatan dan kesehatan kerja juga merupakan tanggungjawab dari perusahaan dan karyawannya.

Untuk mengurangi atau menghilangkan bahaya yang dapat menyebabkan kecelakaan di tempat kerja diperlukan manajemen resiko yang kegiatannya meliputi identifikasi bahaya, analisis potensi bahaya, dan pengendalian resiko bahaya. Dalam proses identifikasi memerlukan analisis potensi bahaya maka dapat dilakukan dengan menggunakan Hazard Identification and Risk Assessment (HIRA). HIRA bertujuan untuk mengidentifikasi potensi bahaya ditempat kerja yaitu dengan mengkaitkan antara pekerja, tugas, perlatan kerja dan lingkungan kerja [3].

Tujuan penelitian yang dilakukan pada penelitian ini adalah mengetahui nilai risiko dan bahaya dari suatu kegiatan kerja pada PT. XYZ yang mana PT. XYZ ini merupakan salah satu perusahaan industri baja berskala besar di Indonesia yang sebagian besar proses produksinya menggunakan mesin dan peralatan yang memiliki potensi bahaya tinggi apabila tidak dilakukan pengendalian.

\section{METODE PENELITIAN}

Tahapan yang dilakukan dalam perancangan ini dapat dilihat pada Gambar 1. Penelitian ini dimulai dengan studi literatur dan observasi lapangan, kemudian menemukan rumusan masalah, tujuan penelitian dan batasan masalah, selanjutnya pengumpulan data yang dilakuakan dengan cara wawancara kepada beberapa petugas yang berkaitan dengan penelitian dan kemudian analisis dan pengolahan data menggunakan metode HIRARC [4].
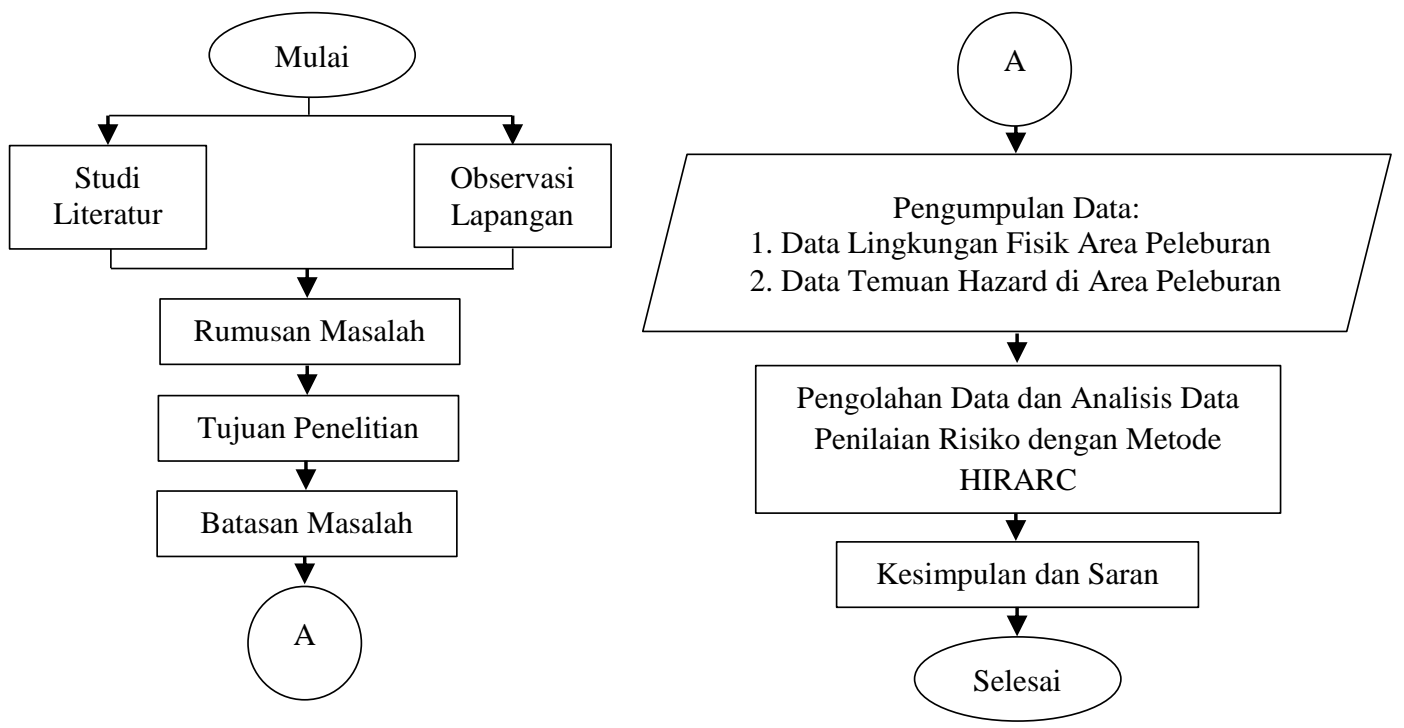

Gambar 1. Flowchart Metodologi Penelitian 


\section{HASIL DAN PEMBAHASAN}

Pada metode HIRARC terdapat tiga tahapan dalam melakukan penelitian, yaitu mengidentifikasi bahaya, penilaian risiko dan pengendalian risiko [4-8].

\section{Identifikasi Bahaya}

Berdasarkan pengamatan yang telah dilakukan pada proses peleburan, terdapat 3 jenis aktivitas yaitu setting panel, proses memasak logam, dan pengujian sample cairan logam. Dari ketiga aktivitas pada proses peleburan terdapat 10 temuan hazard. Berikut tabel temuan hazard pada ketiga aktivitas proses area peleburan.

Tabel 1. Temuan Hazard pada proses peleburan

\begin{tabular}{cll}
\hline No & \multicolumn{1}{c}{ Aktivitas Proses } & \multicolumn{1}{c}{ Temuan Hazard } \\
\hline 1 & Setting Panel & Kebisingan mesin panel \\
2 & Proses Peleburan/peleburan & Panas cahaya dan asap dari tungku \\
& & Percikan cairan logam \\
& & Kebisingan mesin tungku dan sekitarnya \\
3 & Proses Sampling & Percikan api pada saat proses pemotongan sample \\
& & Pekerja terkena pisau gerinda \\
& & Kebisingan mesin gerinda \\
& & Besi sample panas \\
& & Menghaluskan besi tidak menggunakan alat bantuan \\
& & Besi sample dapat terjatuh \\
\hline
\end{tabular}

\section{Setting Panel}

Aktivitas setting panel dilakukan pada awal proses peleburan dan operator harus tetap mengontrol keadaan panel setiap 30 menit untuk memastikan keadaan tungku tetap normal. Pada aktivitas ini terdapat hazard yang ditemukan yaitu kebisingan, temuan hazard ini berasal dari keluhan operator panel. Bahaya kebisingan yang dapat dirasakan oleh pekerja adalah sakit kepala dan gangguan pendengaran jika terpapar kebisingan dalam waktu yang lama. Berdasarkan hasil wawancara, operator merasa sakit kepala saat beberapa hari pertama ditempatkan dibagian panel pada pada saat itu operator belum di fasilitasi APD berupa earplug atau alat pelindung telinga lainnya.

\section{Proses Peleburan}

Proses peleburan merupakan aktivitas utama yang dilakukan dalam proses peleburan scrap-scrap logam. Dalam proses ini di dalamnya meliputi beberapa aktivitas seperti memasukan bahan baku, memasukan batuan, melakukan pengecekan suhu dan meningkatkan suhu ketika dibutuhkan. Dari banyaknya aktivitas yang dilakukan, maka terdapat beberapa hazard yang ditemukan pada proses ini yaitu terpapar panas cahaya dan asap dari proses peleburan, terdapat percikan cairan logam, dan kebisingan yang berasal dari mesin tungku dan sekitarnya. Ketiga temuan hazard tersebut dapat membahayakan fisik maupun kesehatan operator.

Terpaparnya panas cahaya dan asap dapat mempengaruhi kesehatan mata dan juga pernapasan operator, kondisi operator yang bekerja selama 12 jam dan terkena panas cahaya akan membuat operator dehidrasi jika tidak diimbangi dengan mengkonsumsi air mineral secara teratur, selain itu operator akan mengalami mata terasa kering dan gatal sehingga dapat menyebabkan iritasi dan gangguan penglihatan. Sementara itu jika menghirup asap selama proses peleburan tanpa menggunakan APD yang sesuai dapat menyebabkan radang pada tenggorokan hingga gangguan pada saluran pernapasan seperti asma, bronchitis dan yang paling parah kanker paru-paru.

Temuan hazard lainnya yaitu terdapat percikan cairan logam, percikan cairan logam ini dapat membahayakan operator apabila terkena langsung kebagian kulit operator hingga 


\section{Rani Aulia Imran}

melepuh dan parahnya bisa menimbulkan gangguan penglihatan jika terkena pada area mata. Terpapar cairan logam diakibatkan karena operator tidak menggunakan APD lengkap. Munculnya percikan cairan logam disebabkan dari berbagai hal, seperti memasukan batuan Si dan Mn dengan posisi yang salah, terdapat bahan baku yang menimbulkan ledakan dan akibat dari proses penambahan suhu cairan.

Temuan hazard yang selanjutnya adalah kebisingan pada mesin tungku dan sekitarnya. Sama halnya seperti kebisingan pada panel, kebisingan dari mesin tungku juga dapat mempengaruhu kondisi kesehatan operator. Operator akan merasa sakit kepala karena terpapar kebisingan dengan level yang tinggi dan dalam waktu yang lama. Jika paparan kebisingan yang cukup parah terjadi berulang-ulang maka akan berpengaruh pada pendengarannya, sehingga terjadi gangguan pendengaran.

\section{Proses Sampling}

Pada proses sampling terbagi menjadi beberapa aktivitas, seperti pengambilan sample, pemotongan dan penghalusan sample, dan pengujian kompsisi sample. Dari aktivitas-aktivitas yang dilakukan pada proses sampling terdapat 6 temuan hazard yaitu percikan api dan gram pada saat proses pemotongan dan penghalusan sample, mata pisau mesin gerinda tajam, kebisingan mesin gerinda, besi sample dalam keadaan panas, menghaluskan besi sample tidak menggunakan alat bantu dan besi sample dapat terjatuh. Dari keenam hazard yang ditemukan, masing-masing memiliki akibatnya seperti terjadinya iritasi mata, gangguan penglihatan, gangguan saluran pernapasan, dan luka goresan pada tangan karena efek dari terpaparnya percikan api dan gram pada saat proses pemotongan dan penghalusan sample. Mengalami luka robek akibat tersayat mata pisau mesin gerinda. Sakit kepala dan gangguan pendengaran akibat terpapar kebisingan mesin gerinda.

Sementara akibat dari besi sample dalam keadaan panas adalah kulit memerah apabila proses pengujian tidak menggunakan sarung tangan. Dan pada kegiatan menghaluskan besik tidak menggunakan alat bantu akan menyebabkan adanya luka robek jika tangan tergores mesin gerinda. Sedangkan pada kemungkinan besi sample dapat terjatuh akan mengakibatkan luka robek karena sisi dari besi sample lumayan tajam dan memar pada kaki apabila besi sample jatuh menimpa kaki.

\section{Penilaian Risiko}

Risk rating merupakan hasil perkalian antara nilai tingkat likelihood dengan nilai consequences dari masing masing hazard. Penentuan besar nilai likelihood dan severity dari masing-masing risiko bahaya dilakukan dengan cara wawancara kepada bagian K3. Setelah nilai likelihood dan consequences telah didapatkan, selanjutnya mencari nilai risk rating dengan cara mencocokan nilai likelihood dengan nilai consequences yang diperoleh pada gambar 3.2. Berikut adalah hasil risk rating dari masing-masing temuan hazard pada proses peleburan/peleburan logam.

Tabel 2. Penilaian Risiko

\begin{tabular}{clllccc}
\hline No & Temuan Hazard & & \multicolumn{1}{c}{ Risiko } & Akibat & C & R \\
\hline \multirow{2}{*}{1} & Kebisingan mesin panel & Membisingkan Telinga & Sakit Kepala & D & 1 & L \\
& & operator & Gangguan pendengaran & D & 3 & M \\
2 & Panas cahaya dan asap & Terpapar panas dan & Dehidrasi & D & 1 & L \\
& dari tungku & fume & Mata Kering Terasa Gatal & B & 2 & M \\
& & Iritasi Mata & C & 2 & M \\
& & Gangguan Penglihatan & D & 3 & M \\
& & Radang pada tenggorokan & C & 2 & M \\
& & Gangguan saluran pernapasan & C & 3 & H \\
\hline
\end{tabular}


Lanjutan Tabel 2. Penilaian Risiko

\begin{tabular}{|c|c|c|c|c|c|c|}
\hline No & Temuan Hazard & Risiko & Akibat & $\mathbf{L}$ & C & $\mathbf{R}$ \\
\hline \multirow[t]{2}{*}{4} & \multirow[t]{2}{*}{ Percikan cairan logam } & \multirow{2}{*}{$\begin{array}{l}\text { Terkena percikan cairan } \\
\text { logam }\end{array}$} & Kulit melepuh & $\mathrm{C}$ & 2 & $\mathrm{M}$ \\
\hline & & & Gangguan Penglihatan & $\mathrm{D}$ & 3 & M \\
\hline \multirow[t]{2}{*}{5} & \multirow{2}{*}{$\begin{array}{l}\text { Kebisingan mesin } \\
\text { tungku dan sekitarnya }\end{array}$} & \multirow{2}{*}{$\begin{array}{l}\text { Membisingkan Telinga } \\
\text { operator }\end{array}$} & Sakit Kepala & $\mathrm{C}$ & 1 & $\mathrm{~L}$ \\
\hline & & & Gangguan pendengaran & B & 3 & $\mathrm{H}$ \\
\hline \multirow[t]{4}{*}{6} & \multirow{4}{*}{$\begin{array}{l}\text { Percikan api dan gram } \\
\text { pada saat proses } \\
\text { pemotongan dan } \\
\text { penghalusan sample }\end{array}$} & \multirow[t]{4}{*}{ Terkena percikan gram } & Iritasi Mata & $\mathrm{C}$ & 2 & M \\
\hline & & & Gangguan penglihatan & $\mathrm{C}$ & 3 & $\mathrm{H}$ \\
\hline & & & Gangguan saluran pernapasan & $\mathrm{C}$ & 3 & $\mathrm{H}$ \\
\hline & & & Luka goresan pada tangan & B & 1 & M \\
\hline 7 & $\begin{array}{l}\text { Pekerja terkena pisau } \\
\text { gerinda }\end{array}$ & $\begin{array}{l}\text { Tersayat mata pisau } \\
\text { gerinda }\end{array}$ & Luka robek & $\mathrm{E}$ & 3 & M \\
\hline \multirow[t]{2}{*}{8} & \multirow{2}{*}{$\begin{array}{l}\text { Kebisingan mesin } \\
\text { gerinda }\end{array}$} & \multirow{2}{*}{$\begin{array}{l}\text { Membisingkan Telinga } \\
\text { operator }\end{array}$} & Sakit Kepala & $\mathrm{C}$ & 1 & $\mathrm{~L}$ \\
\hline & & & Gangguan pendengaran & B & 3 & $\mathrm{H}$ \\
\hline 9 & Besi sample panas & Terkena besi panas & Kulit memerah & $\mathrm{C}$ & 1 & $\mathrm{~L}$ \\
\hline 10 & $\begin{array}{l}\text { Menghaluskan besi } \\
\text { tidak menggunakan alat } \\
\text { bantuan }\end{array}$ & Tergores mesin gerinda & Luka robek & $\mathrm{C}$ & 2 & M \\
\hline \multirow[t]{2}{*}{11} & \multirow{2}{*}{$\begin{array}{l}\text { Besi sample dapat } \\
\text { terjatuh }\end{array}$} & \multirow{2}{*}{$\begin{array}{l}\text { Kaki tertimpa besi } \\
\text { sample }\end{array}$} & Luka Robek & D & 2 & $\mathrm{~L}$ \\
\hline & & & Memar pada kaki & $\mathrm{C}$ & 2 & M \\
\hline
\end{tabular}

Dari hasil penilaian risiko pada proses peleburan logam didapat 23 dampak/akibat dari risiko-risiko bahaya yang ditemukan. Dan terdapat 3 level risk rating yang ada pada proses peleburan ini dimana terdapat 6 dampak berada pada level low, 12 dampak berada pada level medium dan 5 dampak berada pada level high. Artinya persentase paling besar yaitu pada level medium dengan nilai 52\%, selanjutnya pada level low dengan nilai persentase $26 \%$ dan persentase paling rendah pada level high dengan nilai $22 \%$.

\section{Pengendalian risiko}

Dari beberapa dampak yang terjadi akibat dari hazard yang ditemukan dapat dicegah dengan melakukan control (pengendalian), pengendalian dilakukan secara sistematis mengikuti hirarki pengendalian yaitu: eliminasi, substitusi, rekayasa engineering, administrasi, dan penggunaan APD. Adapun control (pengendalian) yang telah dilakukan perusahaan untuk mengurangi risiko-risiko yang mungkin terjadi sebagai berikut.

Adapun control (pengendalian) yang telah dilakukan perusahaan untuk mengurangi risiko-risiko yang mungkin terjadi sebagai berikut.

\section{a. Pemasangan Cerobong Asap}

Untuk mengurangi risiko akibat terpapar panas dan fume, perusahaan telah melakukan pengendalian dengan membuat cerobong asap di atas tungku yang berfungsi untuk mengalirkan asap dari proses produksi ke filter akhir sehingga asap tidak menyebar ke area produksi, tetapi masih terdapat kekurangan yaitu ketika terjadi angin yang kencang asap tersebut akan menyebar ke area produksi.

\section{b. Penggunaan APD}

Alat Pelindung Diri selanjutnya disingkat APD adalah suatu alat yang mempunyai kemampuan untuk melindungi seseorang yang fungsinya mengisolasi sebagian atau seluruh tubuh dari potensi bahaya di tempat kerja. Seperti yang tertera dalam peraturan menteri bahwa perusahaan wajib menyediakan APD ber-SNI yang diberikan secara cuma cuma kepada pekerja/operator [9]. Maka dari itu perusahaan menyediakan dan memerintahkan kepada operator untuk menggunakan APD sesuai dengan jenis pekerjaannya. 
Tabel 3. Penggunaan APD sesuai dengan Aktivitas yang Dilakukan

\begin{tabular}{cl}
\hline \multicolumn{1}{c}{ Aktivitas } & APD yang digunakan \\
\hline Setting Panel & Earplug \\
& Masker \\
& Safety Shoes \\
Proses Peleburan & Helm \\
& Earplug \\
& Kacamata \\
& Masker \\
& Sarung Tangan \\
& Safety Shoes \\
& Wearpack \\
Proses Sampling & Helm \\
& Earplug \\
& Kacamata \\
& Masker \\
& Sarung Tangan \\
& Safety Shoes \\
& Wearpack \\
&
\end{tabular}

Penentuan dalam penggunaan APD pada tabel di atas disesuaikan dengan fungsi dan jenis pekerjaannya sebagaimana telah diatur pada PERATURAN MENTERI TENAGA KERJA DAN TRANSMIGRASI REPUBLIK INDONESIA NOMOR PER.08/MEN/VII/2010 TENTANG ALAT PELINDUNG DIRI.

\section{c. Menggunakan Ragum pada Mesin Potong Gerinda}

Pada proses pemotongan besi sample, perusahaan telah melakukan pengendalian dengan menggunakan ragum sebagai pengunci besi sample pada saat proses pemotongan. Sehingga operator tidak perlu lagi memegang besi sample, dengan menggunakan alat bantu berupa ragum pada saat proses pemotongan besi sample, perusahaan berharap dapat menghilangkan risiko kecelakaan yang diakibatkan karena terkena mata pisau mesin gerinda.

\section{d. Alat Penangkal Petir}

Dengan kondisi lingkungan kerja yang proses produksinya sangat bergantung dengan tenaga listrik, maka perusahaan dan operator perlu memperhatikan kondisi tegangan listrik agar tidak berakibat buruk kepada operator ataupun terhadap jalannya proses produksi. Maka dari itu pengendalian yang telah dilakukan oleh perusahaan adalah dengan menyiapkan alat penangkal petir yang ditanam di dalam tanah untuk membelokan tegangan listrik yang keluar dari batas toleransi kedalam tanah sehingga tidak membahayakan operator ataupun merusak peralatan.

\section{e. Menyediakan Air Minum}

Paparan lingkungan kerja fisik seperti lingkungan kerja panas yang terus berlanjut dapat mengakibatkan gangguan kesehatan, salah satunya adalah dehidrasi. Untuk menghindari terjadinya dehidrasi operator perlu mendapat asupan cairan yang cukup untuk menjaga kesehatan dan produktivitas pekerja selama bekerja. Dalam lingkungan kerja yang panas operator memerlukan sekurang - kurangnya 2,8 liter/hari, sedangkan untuk pekerjaan dengan suhu lingkungan tidak panas membutuhkan air dianjurkan sekurang-kurangnya 1,9 liter/hari [10]. 
Untuk itu, perusahaan melakukan pengendalian dengan menyediakan air minum dalam jumlah yang banyak di dalam galon berukuran besar, yang ditempatkan dekat dengan area peleburan dan selalu memastikan ketersediaan air minum di dalamnya. Dengan menyediakan air minum didekat area peleburan, diharapkan operator mendapatkan asupan cairan yang cukup sehingga terhindar dari dehidrasi.

Dari beberapa upaya yang telah dilakukan perusahaan dalam mengendalikan risiko bahaya, ada beberapa perbaikan dan usulan yang perlu dilakukan, yaitu pada substitusi, engineering control, administrative control dan alat pelindung diri.

1) Substitusi

a. Mengganti tungku terbuka menjadi tungku tertutup

2) Engineering Control

a. Menggunakan alat pada saat memasukan batuan Si dan Mn.

b. Mengisolasi sumber kebisingan yang ada agar tidak meluas.

3) Administrative Control

a. Menyarankan prosedur atau instruksi kerja

4) Alat Pelindung Diri

a. Menyarankan SOP penggunaan APD

b. Melakukan pendisiplinan penggunaan APD

\section{KESIMPULAN}

Berdasarkan penelitian yang sudah dilakukan, didapatkan kesimpulan bahwa pada area peleburan dengan 3 aktivitas terdapat 10 temuan hazard dengan 23 risiko kecelakaan dan penyakit akibat kerja yang terdapat di 3 tempat. Dengan 2 risiko dari area setting panel, 10 risiko dari area proses peleburan dan 11 risiko dari proses sampling. Dari 23 risiko kecelakaan dan penyakit kerja terdapat 6 risiko pada level low, 12 risiko pada level medium, 5 risiko pada level high. Dengan risiko bahaya yang tinggi perusahaan telah melakukan beberapa pengendalian untuk mengurangi risiko kecelakaan dan penyakit akibat kerja yaitu dengan memasang cerobong asap, penggunaan APD, menggunakan ragum pada mesin potong gerinda, memasang alat penangkal petir, dan menyediakan air minum untuk operator.

\section{DAFTAR PUSTAKA}

[1] B.,Endroyo, 2010. Faktor-faktor Yang Berperan Terhadap Peningkatan Sikap Keselamatan dan Kesehatan Kerja (K3) Para Pelaku Jasa Konstruksi di Semarang. Jurnal Teknik Sipil Fakultas Teknik, Universitas Negeri Semarang, 12(2).

[2] BPJS Ketenagakerjaan, (2019). Angka Kecelakaan Kerja Cenderung Meningkat, BPJS Ketenagakerjaan Bayar Santunan Rp1,2 Triliun. Usenet post to bpjsketenagakerjaan.go.id, diakses September 2019.

[3] Y., Setyaningsih, I., Wahyuni, dan S., Jayanti, 2010. Analisis Potensi Bahaya dan Upaya Pengendalian Risiko Bahaya pada Pekerja Pemecah Batu. Literal Jurnal Kesehatan Masyarakat, Vol. 9, No.1.

[4] S. N. Trisaid., 2020. Analisis Risiko Kecelakaan Kerja Pada Kegiatan Rig Service Menggunakan Metode HIRARC Dengan Pendekatan FTA. Jurnal Ilmiah Teknik Industri: Jurnal Keilmuan Teknik dan Manajemen Industri, Vol.8, No.1, pp. 25-33.

[5] V.E Laksana, W. Kosasih, C.O.Doaly, 2018. Analisis Potensi Bahaya Menggunakan Metode HIRADC Sebagai Upaya Pencegahan Kecelakaan Kerja (Studi Kasus: PT. Supreme Cable Manufacturing \& Commerce). Prosiding Seminar Nasional SNTS III, Jakarta, pp. 251-257. 
[6] A.M. Saedi, J.J. Thambirajah, A. Pariatamby. 2014. A HIRARC model for safety and risk evaluation at a hydroelectric power generation plant, Safety Science, Vol. 70, pp. 308-315.

[7] A Wijaya. T.W.S. Panjaitan, H.C Palit, 2015. Evaluasi Kesehatan dan Keselamatan Kerja dengan Metode HIRARC pada PT. Charoen Pokphand Indonesia. Jurnal Tirta, 3(1).

[8] Menteri Tenaga Kerja dan Transmigrasi, 2010. Peraturan Menteri Tenaga Kerja Dan Transmigrasi Republik Indonesia Nomor Per.08/Men/VII/2010 Tentang Alat Pelindung Diri, Jakarta: Menteri Tenaga Kerja Dan Transmigrasi.

[9] P.K., Suma'mur, 1981. Keselamatan Kerja dan Pencegahan Kecelakaan. Penerbit CV. Haji Masagung, Jakarta.

[10] T. Ihsan, T. Edwin, R.O. Irawan, 2016. Analisis Resiko K3 Dengan Metode HIRARC Pada Area Produksi PT Cahaya Murni Andalas Permai. Jurnal Kesehatan Masyarakat Andalas, Vol. 10, No.2. 